\title{
Laser polishing of additively manufactured Ti-6AI-4V: Microstructure evolution and material properties
}

Solheid, Juliana S.; Mohanty, Sankhya; Bayat, Mohamad; Wunsch, Torsten; Weidler, Peter G.; Seifert, Hans J.; Pfleging, Wilhelm

Published in:

Journal of Laser Applications

Link to article, DOI:

$10.2351 / 7.0000065$

Publication date:

2020

Document Version

Publisher's PDF, also known as Version of record

Link back to DTU Orbit

Citation (APA):

Solheid, J. S., Mohanty, S., Bayat, M., Wunsch, T., Weidler, P. G., Seifert, H. J., \& Pfleging, W. (2020). Laser polishing of additively manufactured Ti-6Al-4V: Microstructure evolution and material properties. Journal of Laser Applications, 32(2), [022019]. https://doi.org/10.2351/7.0000065

\section{General rights}

Copyright and moral rights for the publications made accessible in the public portal are retained by the authors and/or other copyright owners and it is a condition of accessing publications that users recognise and abide by the legal requirements associated with these rights.

- Users may download and print one copy of any publication from the public portal for the purpose of private study or research.

- You may not further distribute the material or use it for any profit-making activity or commercial gain

- You may freely distribute the URL identifying the publication in the public portal 


\section{Laser polishing of additively manufactured Ti-6Al-4V: Microstructure evolution and material properties}

Cite as: J. Laser Appl. 32, 022019 (2020); https://doi.org/10.2351/7.0000065

Submitted: 01 April 2020. Accepted: 01 April 2020. Published Online: 27 April 2020

Juliana S. Solheid, Sankhya Mohanty, Mohamad Bayat, Torsten Wunsch, Peter G. Weidler, Hans J. Seifert, and Wilhelm Pfleging

\section{COLLECTIONS}

Paper published as part of the special topic on Proceedings of the International Congress of Applications of Lasers \& Electro-Optics (ICALEO<sup>\&\#174;</sup> 2019)

Note: This paper is part of the Special Collection: Proceedings of the International Congress of Applications of Lasers

(B)

\& Electro-Optics (ICALEO 2019).
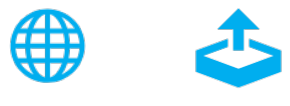


\title{
Laser polishing of additively manufactured Ti-6Al-4V: Microstructure evolution and material properties
}

\author{
Cite as: J. Laser Appl. 32, 022019 (2020); doi: 10.2351/7.0000065 \\ Submitted: 1 April 2020 - Accepted: 1 April 2020 . \\ Published Online: 27 April 2020 \\ Juliana S. Solheid, ${ }^{7}$ Sankhya Mohanty, ${ }^{2}$ Mohamad Bayat, ${ }^{2}$ Torsten Wunsch, ${ }^{3}$ Peter G. Weidler, ${ }^{4}$ Hans J. Seifert, ${ }^{1}$ \\ and Wilhelm Pfleging ${ }^{1,5}$

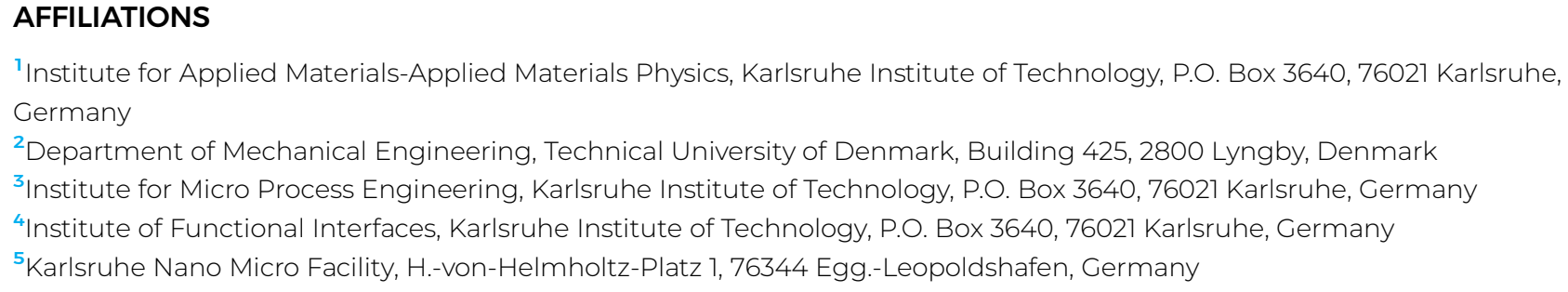

${ }^{1}$ Institute for Applied Materials-Applied Materials Physics, Karlsruhe Institute of Technology, P.O. Box 3640,76021 Karlsruhe, Germany

${ }^{2}$ Department of Mechanical Engineering, Technical University of Denmark, Building 425, 2800 Lyngby, Denmark

${ }^{3}$ Institute for Micro Process Engineering, Karlsruhe Institute of Technology, P.O. Box 3640, 76021 Karlsruhe, Germany

${ }^{4}$ Institute of Functional Interfaces, Karlsruhe Institute of Technology, P.O. Box 3640, 76021 Karlsruhe, Germany

${ }^{5}$ Karlsruhe Nano Micro Facility, H.-von-Helmholtz-Platz 1, 76344 Egg.-Leopoldshafen, Germany

Note: This paper is part of the Special Collection: Proceedings of the International Congress of Applications of Lasers \& ElectroOptics (ICALEO ${ }^{\circledR}$ 2019).

\begin{abstract}
Laser polishing of metals consists of irradiating the part's surface with a laser beam, thus generating a molten layer that is redistributed and resolidified to create a surface with reduced roughness. However, the process is also characterized by an instantaneous formation of heataffected zones with consequent microstructural changes that influence the mechanical properties. In order to understand the microstructural evolution during laser polishing of Ti-6Al-4V laser-based powder bed fusion samples, a thermal model is applied in the current study to predict the dimensions of the melted zones and the heat-affected areas. Furthermore, the results obtained through simulations are discussed and compared to the experimental data, thereby establishing the validity of the process models. Finally, the experimental studies also include the evaluation of material hardness and residual stresses after laser polishing.
\end{abstract}

Key words: additive manufacturing, laser polishing, thermal model, microstructure evolution, material properties

Published under license by Laser Institute of America. https://doi.org/10.2351/7.0000065

\section{INTRODUCTION}

The variety of applications for parts produced by additive manufacturing (AM) is growing with the steady improvement of AM technologies. ${ }^{1}$ Laser-based powder bed fusion (L-PBF) is one of the established AM methods for building metallic parts. Despite many advantages, the L-PBF process is not always capable of providing parts that are ready for use. Often the issue is the low surface quality of the resulting parts, which can present high roughness and porosity levels, thus affecting negatively the mechanical properties. Surface roughness and pores can cause crack formation during fatigue load. ${ }^{2,}$
Laser polishing (LP) is one possibility of postprocessing focused on improving the surface quality of AM parts. The process consists of ablation and/or remelting of the surface through laser radiation, which is redistributed to create a smoother surface., However, the high temperatures achieved during LP can cause extended heat affected zones with consequent microstructural changes that influence the mechanical properties. ${ }^{6,7}$ For a wellinformed decision regarding the set of laser and process parameters to adopt during the LP process and/or the suitable sequencing of LP within the AM process chain, it is important to understand the type of material modification and underlying mechanisms. 
One way of analyzing the surface modifications of the parts during LP while saving material and time is through reliable models. Several approaches have been investigated for the development of accurate models of the LP process. These approaches range from numerical heat transfer combined with fluid flow models to surface predictions considering the asperity of the initial surface and the capillary flow. ${ }^{8-10}$ However, models of such complexity can require a great computational time and capacity.

In this work, an investigation of the resulting microstructure and mechanical properties of AM parts submitted to LP is presented. A straight-forward thermal model is adopted for the fast assessment of the melting depths and the heat affected zones, and experimental studies with Ti-6Al-4V samples are performed for validation of the models and for the analysis of the impact of LP on material hardness and residual stresses. The goal is to provide the ability to use the data obtained from numerical and experimental studies to select the LP process parameters according to the requirements and limitations of the mechanical properties.

\section{MODELLING}

\section{A. Heat transfer model}

The thermal conditions assumed in the heat transfer model adopted in this work are schematically represented in Fig. 1. The laser beam is assumed to be a focused surface heat source that scans the top surface. The top and side surfaces exchange heat with the environment through convection and radiation, while the bottom surface is considered adiabatic. The process simulations were performed on COMSOL Multiphysics 5.4.

The geometry of the used model is presented in Fig. 2. The entire domain has dimensions of $12 \times 4 \times 2 \mathrm{~mm}^{3}$, while the domain scanned by the laser beam has dimensions of $6 \times 1 \times 1 \mathrm{~mm}^{3}$. The maximum mesh element size along the laser affected area is $10^{-4} \mathrm{~m}$.

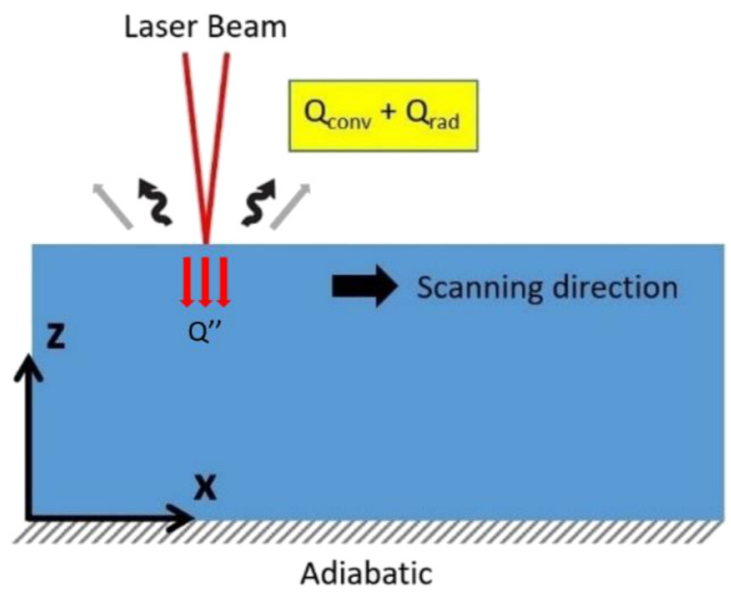

FIG. 1. Schematic drawing of the boundary conditions for the applied heat transfer model.

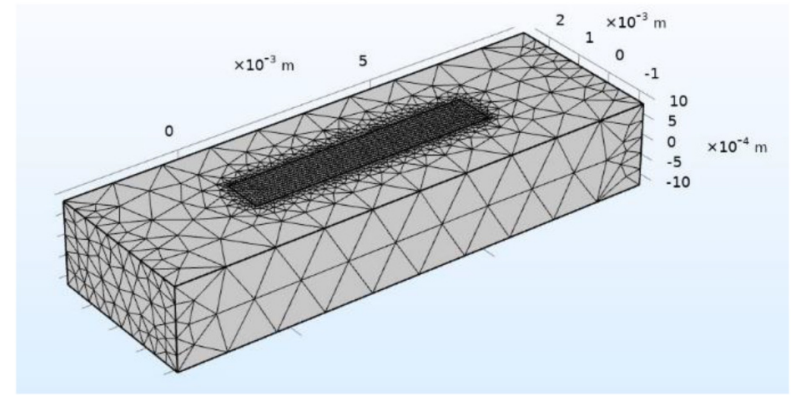

FIG. 2. Geometry and mesh distribution of the present model.

The governing heat transfer equation is expressed in Eq. (1),

$$
\rho C_{\mathrm{p}} \frac{\partial T}{\partial t}=k \nabla^{2} T
$$

where $k$ is the effective thermal conductivity and $C_{\mathrm{p}}$ and $\rho$ are the effective specific heat capacity and density of the material, respectively.

The convection and radiation heat transfer between the side and top surfaces can be described by Eqs. (2) and (3), respectively,

$$
\begin{gathered}
Q_{\mathrm{conv}}=h\left(T_{\mathrm{amb}}-T\right), \\
Q_{\mathrm{rad}}=\varepsilon \sigma\left(T_{\mathrm{amb}}^{4}-T^{4}\right),
\end{gathered}
$$

with $h$ is the convective heat transfer coefficient and $\varepsilon$ and $\sigma$ are the surface emissivity and the Stefan-Boltzman constant, respectively.

$Q^{\prime \prime}$ is the surface heat generation term and is expressed as a Gaussian heat flux as follows:

$$
Q^{\prime \prime}=\frac{2 \alpha P_{w}}{\pi R_{w}^{2}} e^{\frac{-2\left(x^{2}+y^{2}\right)}{R_{w}^{2}}},
$$

where $R_{w}$ is the distance from the center of the heat source, $\alpha$ is the laser absorption coefficient, and $P_{w}$ is the laser power. The values adopted for the described thermophysical properties and simulated process parameters are presented in Table I.

The fluid flow during melting has a great influence on heat dissipation physics and, consequently, on the maximum temperatures achieved during the process. ${ }^{14}$ However, in order to maintain the computational time low, the fluid flow is not directly considered. Instead, the value of liquid thermal conductivity is adapted so the obtained melting and HAZ depths reflect the reality of the experiments.

\section{EXPERIMENTAL SETUP}

\section{A. Material}

The starting material investigated in this work was Ti-6Al-4V blocks manufactured via L-PBF. The samples were analyzed in 
TABLE I. Thermophysical properties of Ti-6Al-4V and simulated process parameters (Refs. 11-13).

\begin{tabular}{lc}
\hline \hline \multicolumn{1}{c}{ Property } & Value \\
\hline Density $(\rho)$ & $4000 \mathrm{~kg} / \mathrm{m}^{3}$ \\
Solidus temperature $\left(T_{\mathrm{s}}\right)$ & $1878 \mathrm{~K}$ \\
Liquidus temperature $\left(T_{\mathrm{l}}\right)$ & $1928 \mathrm{~K}$ \\
Specific heat capacity, solid phase $\left(C_{\mathrm{ps}}\right)$ & $543 \mathrm{~J} / \mathrm{kg} \mathrm{K}$ \\
Specific heat capacity, liquid phase $\left(C_{\mathrm{pl}}\right)$ & $770 \mathrm{~J} / \mathrm{kg} \mathrm{K}$ \\
Thermal conductivity, solid phase $\left(k_{\mathrm{s}}\right)$ & $13 \mathrm{~W} / \mathrm{m} \mathrm{K}$ \\
Thermal conductivity, liquid phase $\left(k_{l}\right)$ & $80 \mathrm{~W} / \mathrm{m} \mathrm{K}$ \\
Laser absorption coefficient $(\alpha)$ & 0.3 \\
Laser power $\left(P_{\mathrm{w}}\right)$ & $300 \mathrm{~W}$ \\
Average scanning speed $(v)$ & $1200 \mathrm{~mm} / \mathrm{s}$ \\
Hatch distance $\left(h_{\mathrm{d}}\right)$ & $50 \mu \mathrm{m}$ \\
\hline
\end{tabular}

three conditions: after the AM process, after heat treatment for stress relief, and after sandblasting. The chemical composition of the material is presented in Table II.

The laser postprocessing was performed on the side (vertical) surfaces of the AM samples, where high roughness due to the attachment of powder and the effects from the layer-by-layer building process was obtained (Fig. 3). The LP was executed ex situ, with the parts being removed from the AM machine and processed in a separate laser system.

\section{B. Laser system}

For the laser polishing process, a combination of TruCell 3010 machine and TruDisk 3001 radiation source (TRUMPF GmbH, laser wavelength $1064 \mathrm{~nm}$ ) was used, which operates in the continuous wave mode. The laser beam is focused onto the sample's surface by lenses BEO D70 with the focal length of $150 \mathrm{~mm}$. During the process, a flow of Argon gas was blown on the surface of the sample by a single nozzle in order to prevent oxidation of the material. The parameters adopted during laser polishing experiments are presented in Table III.

The scanning system works with a pendulum movement (Fig. 4), and common parameters such as average scanning speed and hatch distance are not directly input in the machine. For comparing the simulations and experiments, it is necessary to calculate the average scanning speed and hatch distances. The average scanning speed is the product of the pendulum frequency and four times the amplitude. As for the average hatch distance, it is necessary to first obtain the processing time by dividing the processing length and the axis feed rate and to subsequently calculate how much the laser travelled in the $x$-direction between each scanning line. It is known that the laser scans one line every $0.05 \mathrm{~s}$; based on

TABLE II. Chemical composition (wt. \%) of assessed Ti-6Al-4V produced by L-PBF.

\begin{tabular}{llcccc}
\hline \hline $\mathrm{Ti}$ & $\mathrm{Al}$ & $\mathrm{V}$ & $\mathrm{C}$ & $\mathrm{N}$ & $\mathrm{O}$ \\
\hline 87.5 & 6.4 & 3.9 & 0.01 & 0.001 & 0.1 \\
\hline
\end{tabular}

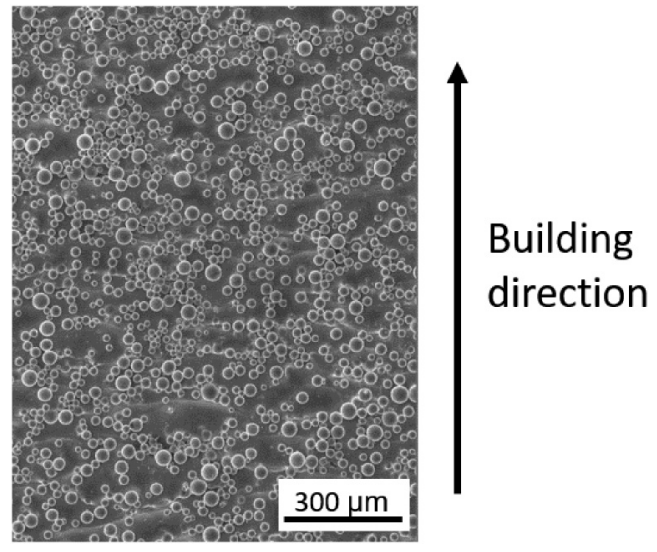

FIG. 3. SEM image of the side surface of the Ti-6Al-4V AM part.

this value and the processing time, it is possible to obtain the number of lines for the entire process and subsequently use the number of lines and the processing length to calculate the average distance between each line.

\section{RESULTS AND DISCUSSION}

\section{A. Melting and heat affected zone}

The first experiments for the validation of the thermal model using properties and parameters described in Table I consisted of the analysis of single tracks. The temperatures obtained during the simulation of the process reached a maximum value of $3500 \mathrm{~K}$ (Fig. 5) that exceeds the melting $\left(1659.85^{\circ} \mathrm{C}\right)$ and boiling $\left(2862^{\circ} \mathrm{C}\right)$ temperature of Ti-6Al-4V. ${ }^{15}$ From the cross section of an experimental single track, it is possible to observe the depths of the melting and heat affected zones (Fig. 6).

When comparing the results obtained with numerical simulation, it is possible to observe that the predicted melting and heat affected zone's shape and depth are very close to three experimental results performed (Fig. 7). The sharp effects on the simulated contours are an effect of coarseness of the mesh, and a smoother more conforming profile is obtained with a finer mesh but with significantly higher computing efforts. The current mesh was selected as

TABLE III. Laser polishing parameters.

\begin{tabular}{lc}
\hline \multicolumn{1}{c}{ Parameter } & Value \\
\hline Beam diameter & $100 \mu \mathrm{m}$ \\
Power & $300 \mathrm{~W}$ \\
Pendulum frequency & $100 \mathrm{~Hz}$ \\
Amplitude & $3 \mathrm{~mm}$ \\
Axis federate & $0.6 \mathrm{~m} / \mathrm{min}$ \\
Processing length & $15 \mathrm{~mm}$ \\
Argon flow rate & $10 \mathrm{l} / \mathrm{min}$ \\
\hline
\end{tabular}



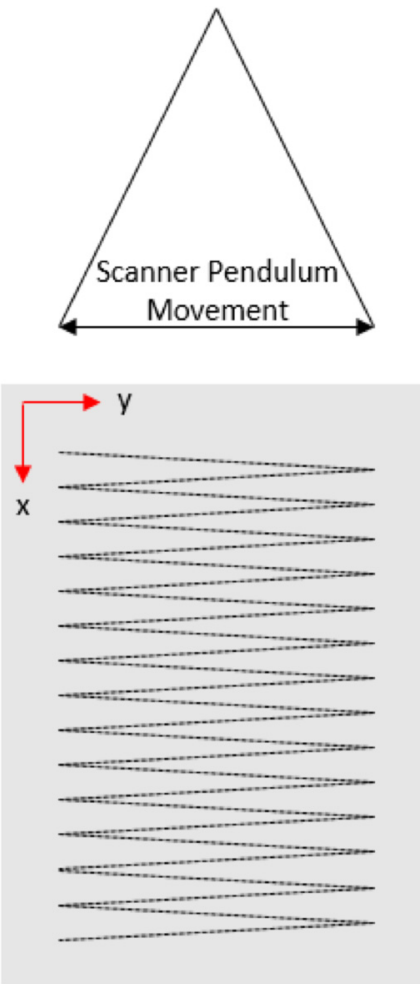

Axis Feedrate

FIG. 4. Schematic view of the laser scanning system used during laser polishing.

it could make prediction within the desired level of accuracy for this study.

After analyzing the experimental melting and heat affected zones of single tracks and validating the proposed model, areal experiments were performed with the parameters presented in Tables I and II. The experiments were performed with the same parameters for the samples with three initial conditions mentioned: as-built $(\mathrm{AB})$, heat treated for stress relief (HT), and sand blasted

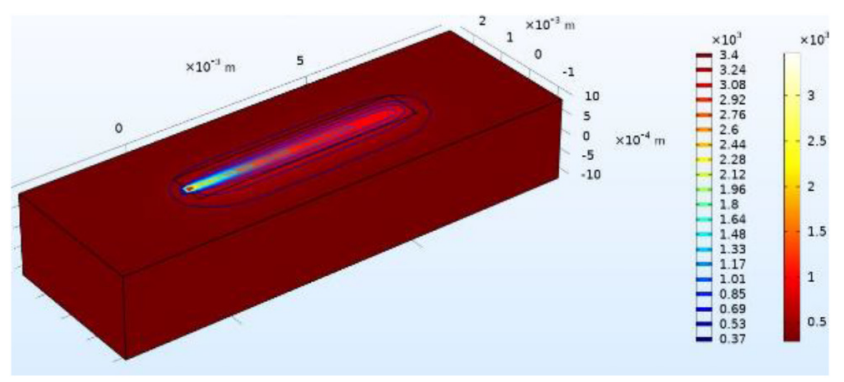

FIG. 5. Results of numerical simulation of temperatures obtained during laser polishing.

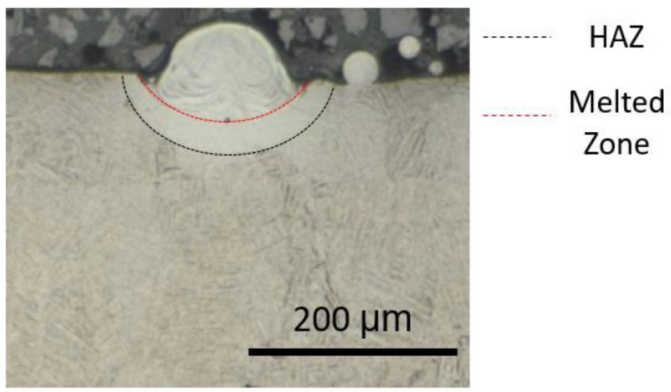

FIG. 6. SEM image of the HAZ and the melted area of a single track experiment.
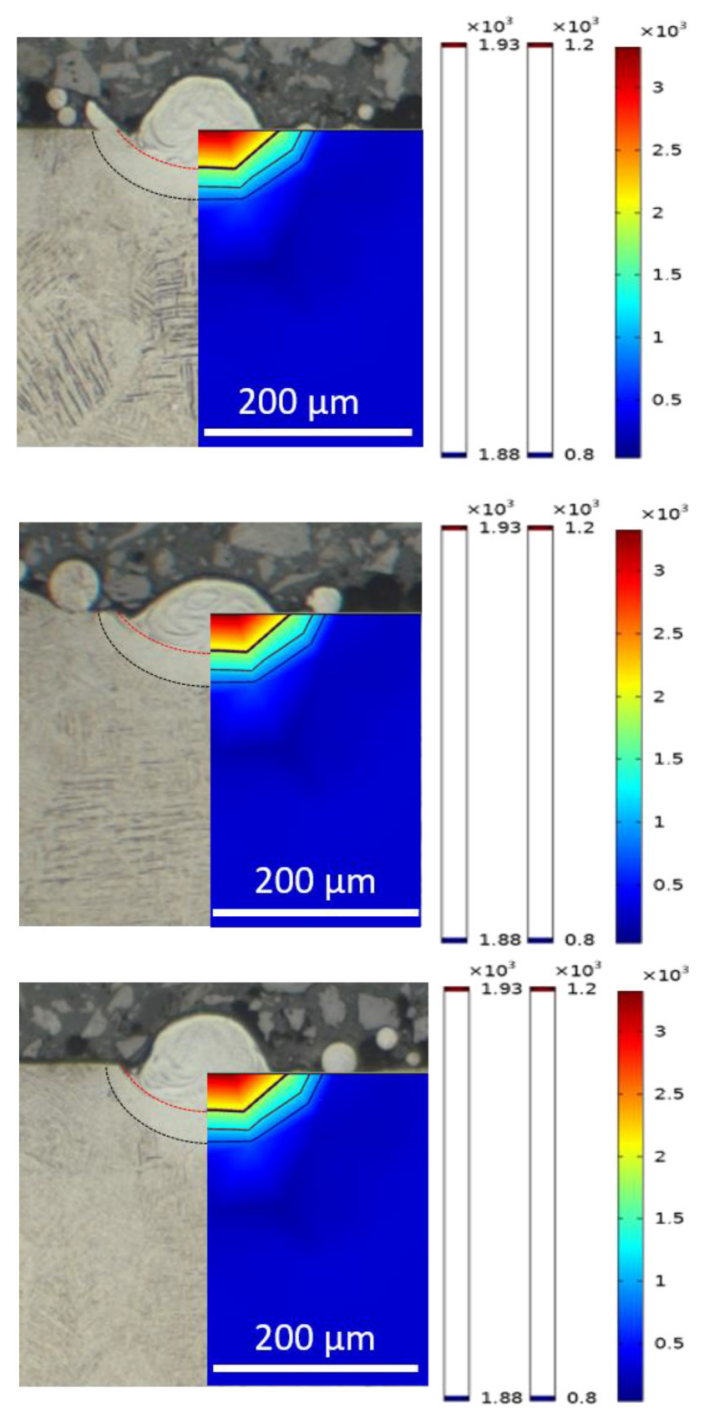

FIG. 7. Comparison of the simulated and experimental depths of the melting and heat affected zones. 


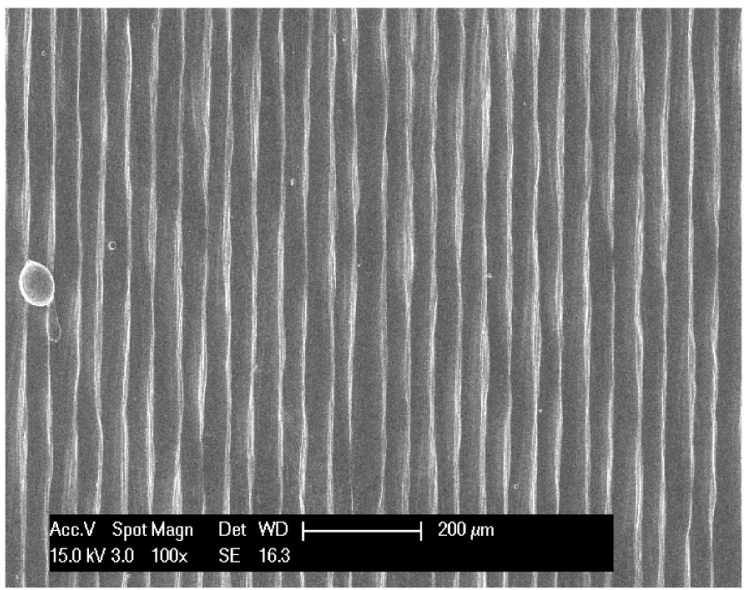

FIG. 8. SEM image of the surface after laser polishing.

after heat treatment (SB). The surface texture after LP presented a clear improvement when compared to the same surface directly after AM, with Ra values of $6.9 \mu \mathrm{m}$ before LP (Fig. 8) and $5.2 \mu \mathrm{m}$ after one repetition of the parameter set adopted (Fig. 3). By repeating the operation three times in the same area, the surface roughness achieved was $0.8 \mu \mathrm{m}$.

The combination of the HAZ and melting zones can be clearly observed in the HT and SB samples [Figs. 9(c) and 9(d)], due to contrasting etching of the metastable $\alpha^{\prime}$ phase of Ti-6Al-4V formed in the melting zone against a typical $\alpha-\beta$ phase in the rest of the sample (obtained during heat treatment after L-PBF). Due to similar high thermal gradients and cooling rates during L-PBF and $\mathrm{LP}$, the overall $\mathrm{AB}$ sample also shows martensitic $\alpha^{\prime}$ phase formation, and therefore, the HAZ and melting zones of LP cannot be clearly distinguished [Fig. 9(b)].

For areal experiments, the HAZ plus melting zones had an average depth of $100 \mu \mathrm{m}$, while for both numerical and experimental single lines, it was in the range of $70 \mu \mathrm{m}$. The different values obtained after the single track and the areal experiments is due to the $50 \%$ overlap between the laser tracks during areal experiments, causing the part to be submitted to more heat over time.

From the presented model, it is possible to obtain different thermal data during the LP process, such as maximum and minimum temperatures, thermal gradients, and cooling rates. In the ongoing work, the present thermal model is coupled with a metallurgical model to obtain predictions for grain morphology and phase fraction. ${ }^{16,17}$ However, these studies are beyond the scope of the presented paper which is focused on the prediction of laser affected zones and the experimental aspects of material

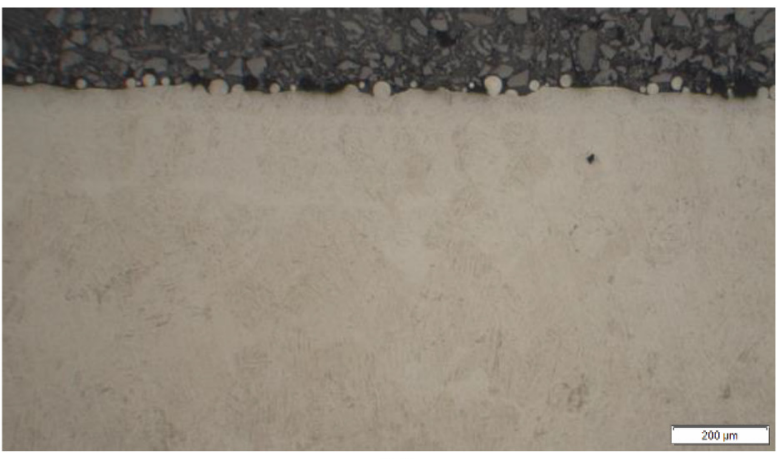

(a)

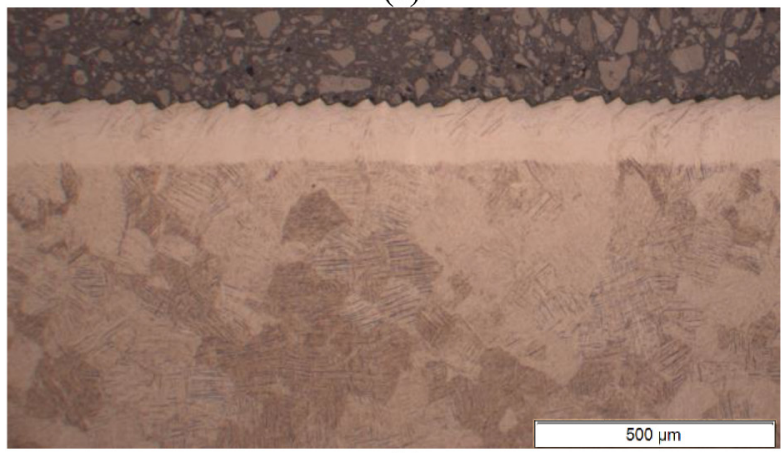

(b)

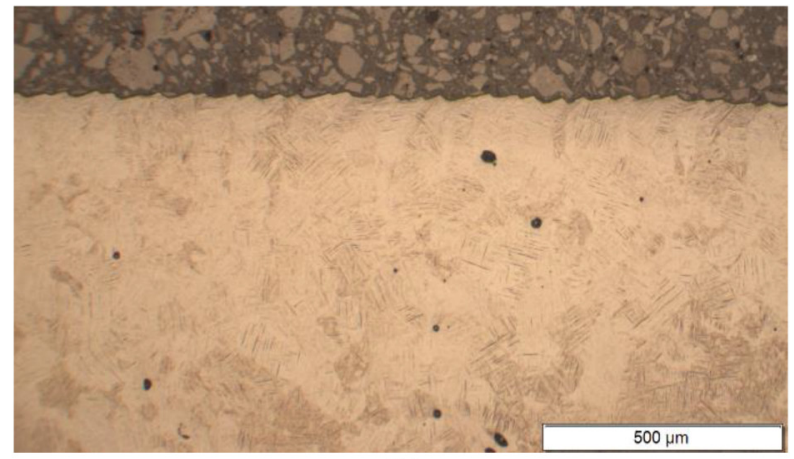

(b)

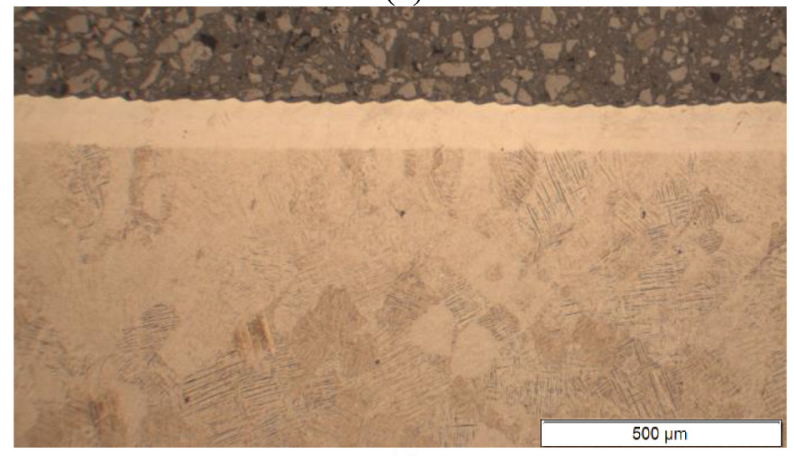

(d)

FIG. 9. Cross section analysis of the $H A Z$ of (a) the $A B$ sample before $L P$, (b) the $A B$ sample after $L P$ areal experiments, (c) the $H T$ sample after $L P$ areal experiments, and (d) the SB sample after LP areal experiments. 


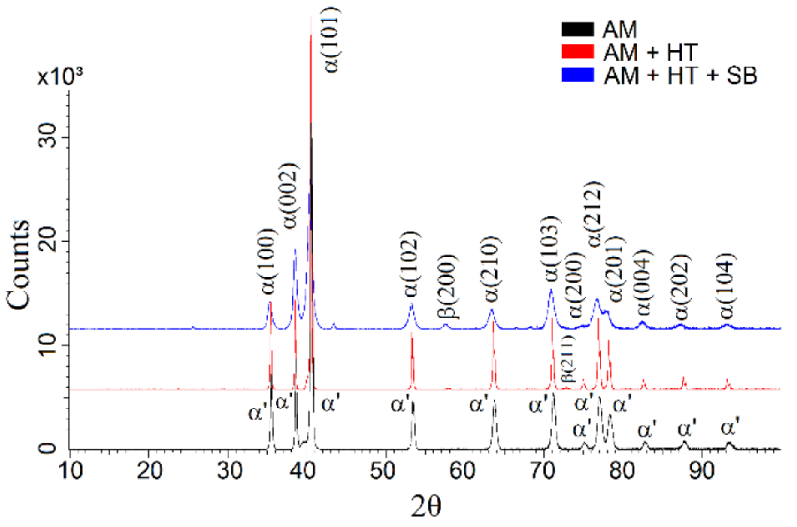

FIG. 10. XRD patterns of $A B(A M), H T$, and $S B$ samples.

characterization throughout different steps of the manufacturing process chain.

\section{B. Phase analysis}

In order to confirm the presence of the expected phases on the samples in the three initial conditions and on the same conditions after LP, XRD analysis was performed.

The patterns obtained for the three initial conditions prior to LP confirmed a majority presence of peaks from the hexagonal (hcp) $\alpha$ phase for the HT and SB samples, while only peaks of the martensitic $\alpha^{\prime}$ phase were identified for the AB sample (Fig. 10). Both $\alpha$ and $\alpha^{\prime}$ phases present a hexagonal crystalline structure, but they differentiate from each other by the higher residual stress state on the martensitic $\alpha^{\prime}$ microstructure. This difference is represented

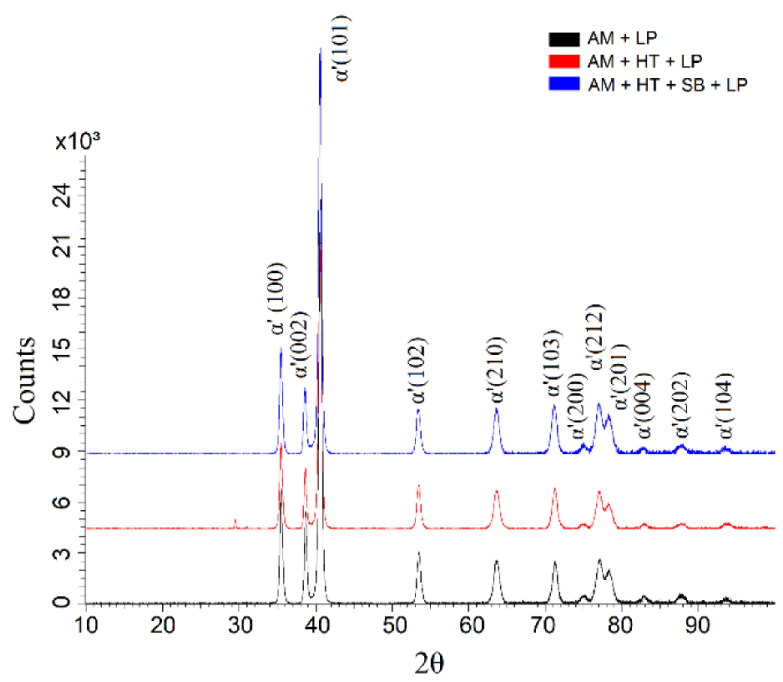

FIG. 11. XRD patterns of the samples: $A B(A M), H T$, and $S B$ after $L P$.

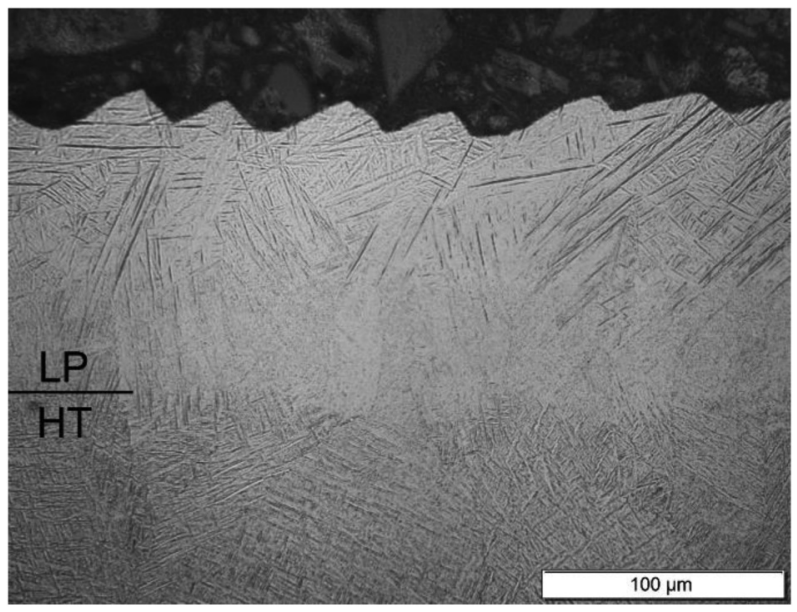

FIG. 12. Cross section analysis: optical image of the Ti-6Al-4V microstructure after LP (top) and HT (bottom).

in the XRD patterns as a slight shift on the $2 \theta$ angle and as the broadening of the peaks. The remaining peaks observed on the HT and SB samples correspond to the body-centered cubic (bcc) $\beta$ phase.

The patterns obtained for the three initial conditions after the LP process presented the exact same peaks for all cases, which match the pattern of only the $\alpha^{\prime}$ phase after laser polishing, with the peak locations and broadening as described above (Fig. 11).

The differences between the microstructures can also be confirmed via optical microscopy analysis, in which the martensitic structure on the laser polished and additive manufactured areas present a thin and elongated needlelike geometry (Figs. 12 and 13),

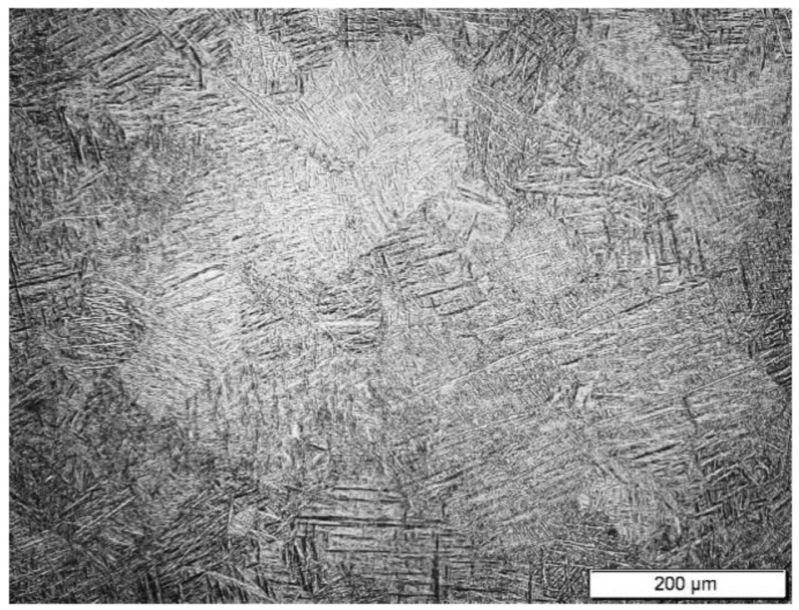

FIG. 13. Optical image of the Ti-6Al-4V microstructure after heat treatment indicating the presence of $\alpha$ (brighter areas) and $\beta$ (darker areas) phases. 


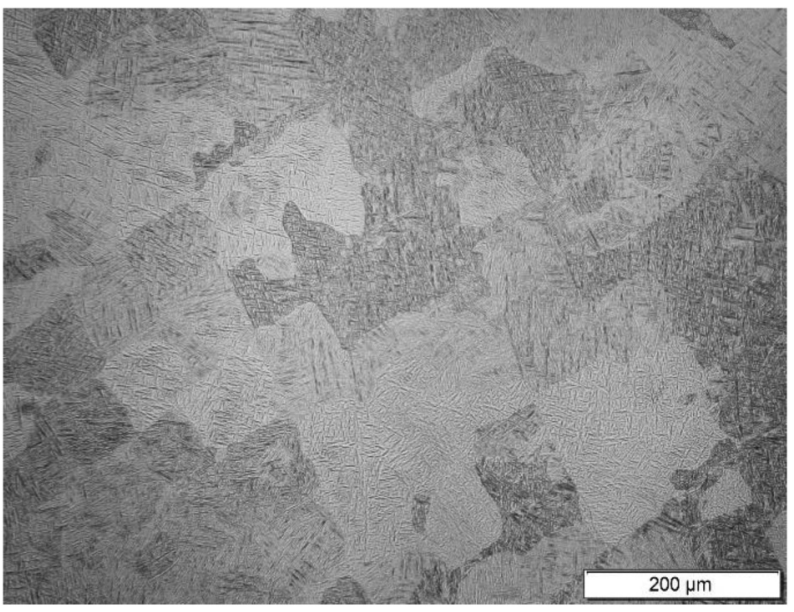

FIG. 14. Optical image of the Ti-6Al-4V microstructure after additive manufacturing with the presence of only $\alpha^{\prime}$ phase.

while the microstructure after heat treatment present a lamellar characteristic (Figs. 12 and 14).

\section{Residual stresses}

As mentioned in Sec. IV B, the stress states of the material varies according to which process it was subjected. To quantify the residual stresses of the analyzed samples in the initial conditions and after LP, the Williamson-Hall plot was used, which relates the peak width and the Bragg angle obtained with the XRD analysis to the crystallite size and lattice strain. ${ }^{18}$

As expected, the heat treated sample (HT) presented a small $\varepsilon_{0}$ value (Fig. 15). Despite heat treatment, the SB sample presented a higher stress state, which can be related to compressive stress caused by the sand particles' jet on the material's surface following the stress relief treatment. The samples submitted to LP presented similar $\varepsilon_{0}$ values for different initial conditions of residual stress, which were between the heat treated and additively manufactured

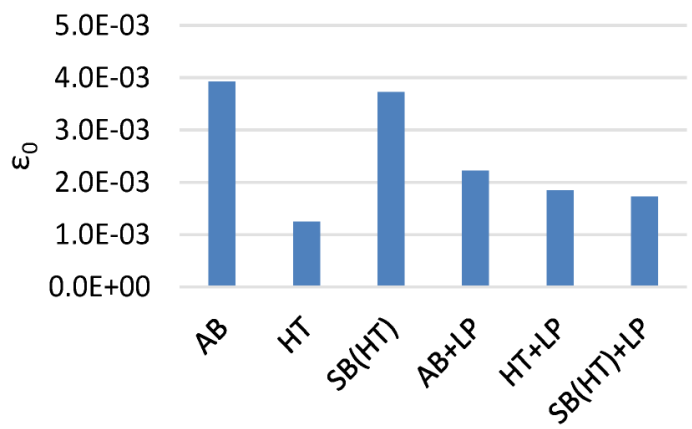

FIG. 15. Residual stresses of Ti-6Al-4V samples after different steps of the manufacturing process.

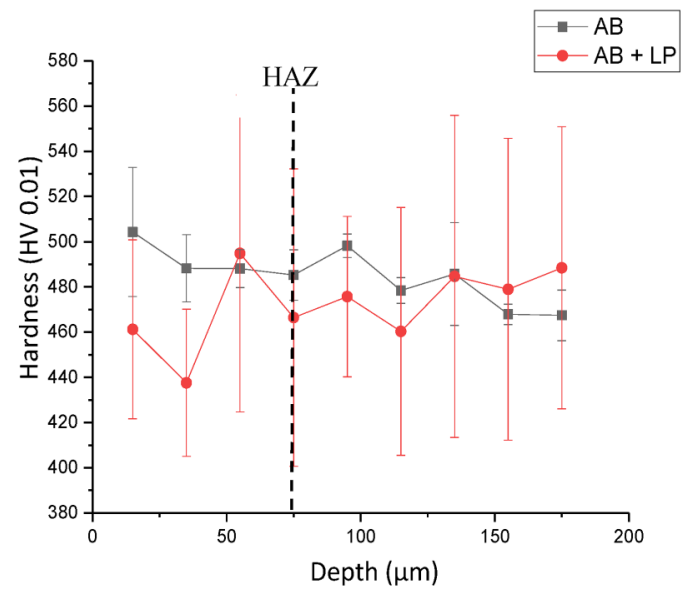

(a)

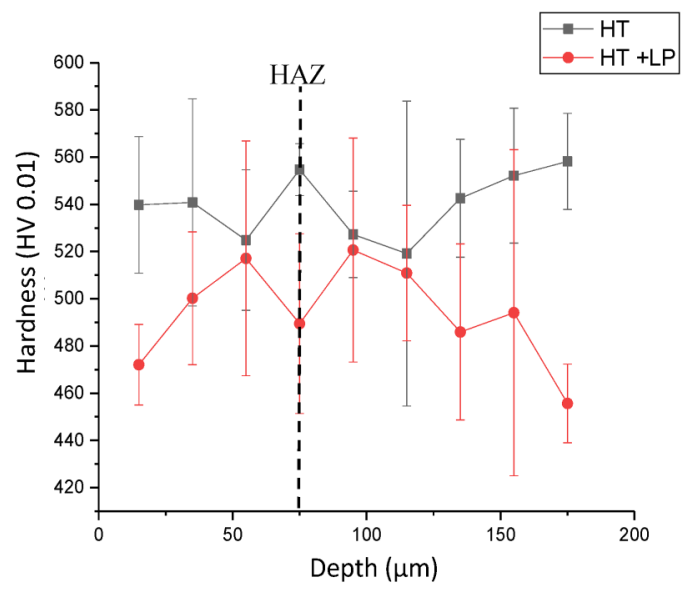

(b)

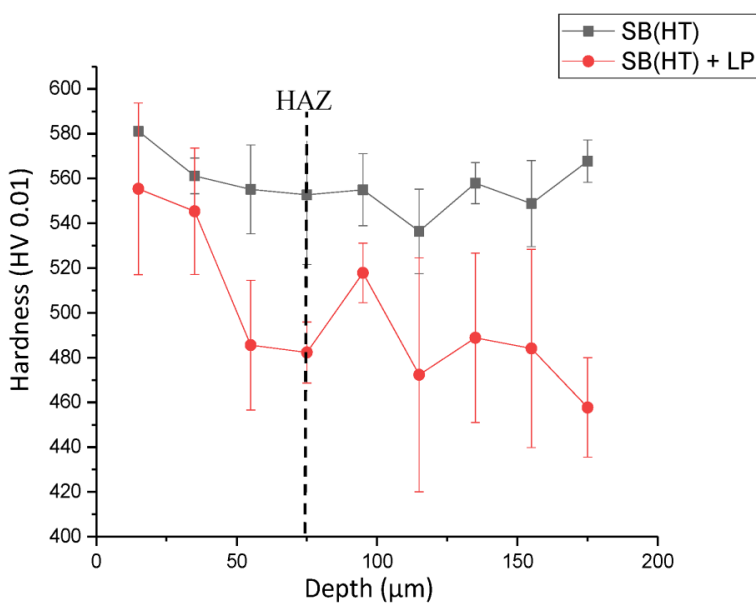

(c)

FIG. 16. Vickers microhardness of Ti-6Al-4V samples before and after laser polishing: (a) AB samples, (b) HT samples, and (c) $\mathrm{SB}(\mathrm{HT})$ samples. 
values. Apart from the similarities of the AM and LP processes, the residual stress in the sample analyzed after the additive manufacturing process presented the highest $\varepsilon_{0}$ value among all samples.

\section{Hardness}

The change in the microstructure and different stress conditions also have their implications on the mechanical properties of the parts.

The martensitic $\alpha^{\prime}$ microstructure is known to present higher values of hardness when compared to $\alpha$ and $\beta$ phases. Although, even with the presence of only the $\alpha^{\prime}$ phase after laser polishing, the values obtained from the Vickers micro hardness showed a decrease in hardness when compared to the HT and SB samples (Fig. 16).

This effect on the hardness can be caused by defects generated during the laser polishing process, i.e., cracks or pores, but these defects were not observed in the LP samples. The magnitude of the error bars and the deviation of the values, even among the laser polished samples, suggest a limitation regarding the repeatability of the measurement system. Furthermore, the expected evident difference in the hardness of the laser polished samples within the HAZ (up to $100 \mu \mathrm{m}$ ) and beyond (over $100 \mu \mathrm{m}$ ) is not observed in the current measurement results.

\section{CONCLUSIONS}

In this work, the analysis of the microstructure evolution and selected mechanical properties for L-PBF Ti-6Al-4V samples in different steps of the process chain was presented together with a heat transfer model for the prediction of the depths of HAZ and melting zone.

In their initial conditions, the samples presented two different types of microstructure, being all $\alpha^{\prime}$ phase for the samples analyzed straight after the AM process and a combination of $\alpha$ and $\beta$ phases for the samples submitted to stress relief heat treatment. After laser polishing, all samples presented the same microstructure evolution with the presence of only the $\alpha^{\prime}$ phase. The stress state of the samples after laser polishing had a significant variation from the initial conditions. The postprocess induced stress in the heat treated samples and acted as a localized stress relief mechanism on the surface of the as-built samples.

With the understanding of changes that occur in the material in the laser affected areas and with a computational model that can rapidly estimate the depth of these zones, it is possible to make a more informed decision about the suitability of laser polishing based on each part's specific requirements.

\section{ACKNOWLEDGMENTS}

This work has received funding from the European Union's programme $\mathrm{PAM}^{2}$ within Horizon 2020 under Grant Agreement No. 721383. The authors would like to thank 3D Systems Leuven for providing samples produced on a DMP Flex 350 machine using
LaserForm Ti Gr23 (A). Furthermore, the support for laser materials processing by the Karlsruhe Nano Micro Facility (KNMF, http:// www.knmf.kit.edu/), a Helmholtz research infrastructure at the Karlsruhe Institute of Technology (KIT), is gratefully acknowledged.

\section{REFERENCES}

${ }^{1}$ L. Chen, Y. He, Y. Yang, S. Niu, and H. Ren, “The research status and development trend of additive manufacturing technology," Int. J. Adv. Manuf. Technol. 89, 3651-3660 (2017).

${ }^{2}$ B. Zhang, Y. Li, and Q. Bai, "Defect formation mechanisms in selective laser melting: A review,” Chin. J. Mech. Eng. 30, 515-527 (2017).

${ }^{3}$ E. Wycisk, A. Solbach, S. Siddique, D. Herzog, F. Walther, and C. Emmelmann, "Effects of defects in laser additive manufactured Ti-6Al-4V on fatigue properties," Phys. Procedia 56, 371-378 (2014).

${ }^{4} \mathrm{~J}$. Kumstel and B. Kirsch, "Polishing titanium- and nickel-based alloys using cw-laser radiation,” Phys. Procedia 41, 362-371 (2013).

${ }^{5}$ F. Zhihao, L. Libin, C. Longfei, and G. Yingchun, "Laser polishing of additive manufactured superalloy,” Proc. CIRP 71, 150-154 (2018).

${ }^{6}$ C. P. Ma, Y. C. Guan, and W. Zhou, "Laser polishing of additive manufactured Ti alloys,” Opt. Laser Eng. 93, 171-177 (2017).

${ }^{7}$ W. J. Wang, K. C. Yung, H. S. Choy, T. Y. Xiao, and Z. X. Cai, "Effects of laser polishing on surface microstructure and corrosion resistance of additive manufactured CoCr alloys," Appl. Surf. Sci. 443, 167-175 (2018).

${ }^{8}$ S. Marimuthu, A. Triantaphyllou, M. Antar, D. Wimpenny, H. Morton, and M. Beard, "Laser polishing of selective laser melted components," Int. J. Machine Tools Manuf. 95, 97-104 (2015).

${ }^{9}$ T. M. Shao, M. Hua, H. Y. Tam, and E. H. M. Cheung, "An approach to modelling of laser polishing of metals,” Surf. Coat. Technol. 197, 77-84 (2005).

${ }^{10}$ Q. Wang, J. D. Morrow, C. Ma, N. A. Duffie, and F. E. Pfefferkorn, "Surface prediction model for thermocapillary regime pulsed laser micro polishing of metals," J. Manuf. Processes 20, 340-348 (2015).

${ }^{11}$ W. Yan, Y. Qian, G. Wenjun, S. Lin, W. K. Liu, F. Lin, and G. J. Wagner, "Meso-scale modeling of multiple-layer fabrication process in selective electro beam melting: Inter-layer/track voids formation," Mater. Des. 141, 210-219 (2018).

${ }^{12}$ L. Parry, I. A. Ashcroft, and R. D. Wildman, "Understanding the effect of laser scan strategy on residual stress in selective laser melting through thermomechanical simulation," Addit. Manuf. 12, 1-15 (2016).

${ }^{13}$ Y. Huang, L. J. Yang, X. Z. Du, and Y. P. Yang, "Finite element analysis of thermal behaviour of metal powder during selective laser melting," Int. J. Therm. Sci. 104, 146-157 (2016).

${ }^{14}$ M. Bayat, S. Mohanty, and J. H. Hattel, "A systematic investigation of the effects of process parameters on heat and fluid flow and metallurgical conditions during laser-based powder bed fusion of Ti6Al4V alloy," Int. J. Heat Mass Trans. 139, 213-230 (2019).

${ }^{15} \mathrm{H}$. Wu, J. Ma, Q. Meng, M. P. Jahan, and F. Alavi, "Numerical modeling of electrical discharge machining of Ti-6Al-4V,” Proc. Manuf. 26, 359-371 (2018).

${ }^{16}$ D. De Baere, M. Bayat, S. Mohanty, and J. Hattel, “Thermo-fluid-metallurgical modelling of the selective laser melting process chain,” Proc. CIRP 74, 87-91 (2018).

${ }^{\mathbf{1 7}}$ V. Bruyere, C. Touvrey, P. Namy, and N. Authier, "Multiphysics modeling of pulsed laser welding,” J. Laser Appl. 29, 022403 (2017).

${ }^{18}$ G. K. Williamson and W. H. Hall, "X-ray line broadening from filed aluminium and wolfram," Acta Metall. 1, 22-31 (1953). 